\title{
Preference and the conversation analytic endeavor
}

Jack Bilmes*

\author{
Department of Anthropology, University of \\ Hawaii, Honolulu, HI 96822, USA \\ Published in Journal of Pragmatics 64 (2014) 52--71
}

\begin{abstract}
Conversation analysis (CA), as currently practiced, comprises two approaches -action-oriented and meaning-oriented. I use CA treatments of 'preference' as a case in point. In current discussions of preference, the emphasis is on action, on what interactants do. Action is grounded in psychological mechanisms, which CA is not equipped to handle. So discussions of preference turn toward a more quantified notion of what people usually do. I argue that attempts at quantification raise problems that are not soluble within the confines of CA methodology. I then turn to the broadest and most discussed preference, the supposed preference for agreement, arguing that it is context sensitive in ways that produce multiple exceptions. Using a gross, transcontextual average, even if that were possible, would be unenlightening. I focus, using an extended example, on one of the exceptions, the case of accusations. I suggest that we drop the action- oriented approach and attend instead to meaning. This approach is grounded in a conception of evidence which does not rely on either falsification criteria or statistical measures. Its generalizations pertain not to what interactants normally do but to the resources they have and the methods they employ in producing meaning and social organization.
\end{abstract}

Conversation analysis (CA) is the study of the organization of talk-in-interaction. It is characterized by a set of methodological techniques and perspectives: primarily, recording of "natural" data, participant orientation, attention to detail ("order at all points"), sequentiality, next turn proof procedure, and deviant case analysis. ${ }^{1} \mathrm{CA}$, as it is currently practiced, comprises two general approaches, which I will refer to as action-oriented $C A$ and meaning-oriented $C A$. In

action-oriented CA, the objective is to specify what conversationalists do, in general or in specific circumstances. The focus is on the production of talk-in-interaction. Meaning-oriented CA concerns itself with the production/expression, potentialization,

1 For illumination on these matters, the uninitiated reader is referred to the wide array of introductory essays and books, from Levenson (1983, chapter 6) and Heritage (1984, chapter 8) to Schegloff (2007) and Sidnell and Stivers (2012). 
and (participant) interpretation of meaning in talk-in-interaction. The distinction can be illustrated with an example from Sacks' (1992:4) first transcribed lecture. Sacks is describing calls to an emergency psychiatric hospital: "If A says 'This is Mr Smith may I help you,' B tends to say 'Yes, this is Mr Brown'." This is an action-oriented formulation (note "tends to"). A few sentences on, though, we get this: "Saying 'This is Mr Smith may I help you' thereby provides a 'slot' to the other wherein they properly would answer 'Yes, this is Mr Brown'" (4). This second formulation is meaning oriented. It speaks of slots created and what is "properly" done rather than what tends to be done. It will be (part of) my argument in this paper that action-oriented CA ultimately involves us in issues of quantification, an area which is, as I will elucidate below, unreachable with CA methodology. I am proposing, therefore, that the action-oriented approach is a very questionable part of the CA endeavor and that the attempt at empirical generalization be abandoned or at least limited in ways that are in accordance with the limitations of CA itself. These "limitations," it should be emphasized, and as I will explain in section 7 of this paper, are essential to CA as an analytic approach. I will use preference theory ${ }^{2}$ to make my argument. Preference has been presented, primarily, in terms of action; I will try to reformulate it within a meaning-oriented approach.

I begin by surveying preference theory as it is presently presented in the literature.

2 I use "preference theory" as a way of referring to the concepts and assertions that comprise the phenomenon of preference organization. 


\section{Preferred responses}

In the last few years, two major expositions of preference theory in conversation analysis have appeared - Schegloff (2007, chapter 5) and Pomerantz and Heritage (2012). (See also Sidnell, 2010, chapter 5.) Both fail to resolve what I see as conceptual problems with the notion of preference. Since the two expositions take rather different approaches, I cannot deal with both simultaneously. Schegloff's is the more orthodox treatment, as well as the more detailed. I will center my critique on his presentation, referring to Pomerantz and Heritage when relevant and appropriate.

Although the notion of preference has been used for various conversational phenomena -- the preference for self- correction (Schegloff et al., 1977), the preference for recognitionals in person reference (Sacks and Schegloff, 1979; Enfield and Stivers, 2007), ${ }^{3}$ the preference for offers over requests (Lerner, 1996; Schegloff, 2007) - I will focus first, and

primarily, on the notion of preferred response and the associated concept of dispreference markers. This is the preference phenomenon which has received the most attention and analytical elaboration. Indeed, Sidnell (2010), in his introduction to $\mathrm{CA}$, devotes his entire chapter on preference to responses, although he mentions in passing that it has been applied to first pair-parts as well. Schegloff, in his chapter on preference, writes at some length about first pair-part preference, but, for reasons of organization and economy, I will not deal with this subject in my current discussion.

Schegloff (2007:59) says that

The key issues in the organization around 'preference' and 'dispreference' concern the alignment in which a second action stands to a first, and the alignment which recipients take up toward a first pair part by the second pair part which implements their response.

The preferred response "embodies an alignment with [the project of] the first pair part" (59). However, later in his chapter, he applies the notion of preference to first pair parts. So, for example, offers (it is claimed) are preferred over requests. Perhaps the common and defining feature of preference across these two formats (i.e., preference as applied to first and to second pair parts) is that production of the preferred alternative is promoted, whereas the dispreferred alternative is avoided or mitigated or delayed or, at least, accounted for.

According to preference theory, certain utterances require responses from a bounded set of alternatives. One alternative is the invited response (Pomerantz,

3 A recognitional is a form which enables recognition of the person referred to. I have suggested elsewhere (Bilmes, 1988, footnote 13) that the preference for recognitionals is not a preference at all, but a matter of implicature. Use of a recognitional implicates that the recipient knows the person referred to; use of a nonrecognitional implicates the opposite. The literature offers many examples of nonrecognitionals being corrected to recognitionals (thus the preference for recognitionals), but the converse also occurs with some frequency. Here is an example from Sacks (1992:44):

A: Corliss, the g- this chick that I'm hanging around with now $((\ldots))$ 
1984), which is said to be preferred. The other(s) is dispreferred. Dispreferred responses are preceded by delays, mitigated, and are accompanied (or constituted) by accounts. These practices are known as dispreference markers. If it is anticipated that a dispreferred response will be forthcoming, the speaker may add to the first pairpart to encourage the production of a preferred response (Davidson, 1984) or alter the first pair-part in such a way as to make the anticipated response a preferred response. Moreover, the absence of a response is, relevantly, the absence of the preferred response, so the dispreferred response is implicated. When a preferred response is produced in association with dispreference markers, the response will be taken to be in some way problematic. This is the early formulation of preference theory, based largely on a 1973 lecture by Harvey Sacks (reprinted in Button and Lee, 1987), as presented in Pomerantz (1984) and many other previous and subsequent publications by various authors (see especially Atkinson and Drew, 1979; Heritage, 1984; Heritage and Watson, 1979; Levenson, 1983; Pomerantz, 1975, 1978). I have mentioned here some foundational writings, but preference theory is still very much alive as indicated not only by the summary pieces by Schegloff and by Pomerantz and Heritage, but by its invocation in numerous recent CA studies.

In fact, if anything, reliance on preference theory seems to be getting stronger and, in particular, wider. Stivers and Robinson (2006) treat the turn-taking rule proposed by Sacks et al. (1974) as a matter of preference. Pomerantz and Heritage (2012) treat a broad range of conversational practices in terms of preference. "The core idea of preference is that participants follow principles, often implicit, when they act and react in a variety of interactional circumstances" (210). (It is not clear to me whether preference is to be associated with all or just a subset of these principles.) Furthermore, departures tend to be treated as resulting from cross-cutting preferences. This makes preference theory a very broad system of explanation of conversational phenomena. There seem to be three major criteria used in these presentations:

1. Regular practice - what conversationalists ordinarily do.

2. Attempts to achieve the preferred outcome. Speakers may, for instance, reformat their utterances if it appears that they are about to receive a dispreferred response.

3. Marked formatting of dispreferred responses - see discussion below.

Note, and I will make this point repeatedly, that these criteria are all focused on utterance production rather than inference or other aspects of meaning production. We might contrast this with Levenson's early (1983) statement that "conversationalists are ... caught in a web of inferences (321, footnote 16; see also Schegloff's [1968] comments on conditional relevance and "naive" choice). 


\section{Preference and choice}

I begin with a point made forcefully by Schegloff. "It is important throughout this discussion of preference and dispreference to keep clearly in focus that it is a socio/interactional feature of sequences and of orientations to them, not a psychological one" (Schegloff, 2007:61, his emphasis). This reflects the general position of preference theorists. ${ }^{4}$ The point here is that the notion of preference in CA does not refer to the actual preferences or desires of individuals. Schegloff (2007:59) argues further that

Sequences are the vehicle for getting some activity accomplished, and that response to the first pair part which embodies or favors furthering or the accomplishment of the activity is the favored---or, as we shall term it, the preferred second pair part.

This seems to make preference part of what Sacks calls the "machinery" of conversation. In this sense, preference might be compared to turn taking.

Although preference, as it has been used in CA, refers to something other than the psychological states of the actors involved, it nevertheless is grounded, as is all action, in individual choice. For illustration, we can examine two instances of what Maynard and Schaeffer (1997) term requests for participation:

\section{(1) Maynard and Schaeffer (1997:38)}

1. MR: Hello:.

2. INT: .hh Ah hello: I'm Greg Sanders calling from the University of

3. Wisconsin .hh as: part of our national public opinion study?

4. .hh a:n:d we are trying to reach people at their home telephone

5. numbers is: this a residential number?

$6 . \quad(0.8)$

7. MR: Uh yes it is but I'm sorry I d- I don't have any time to (.)

8. answer any of your questions [right now]

9. INT: [Oh::: ]kay well we'd like to

10. try you back at another time then would that be alright?

11. MR That'd be fine.

12. INT: O::kay well thank you very much [sir ]

13. MR:

14. INT:

Bye bye.

[Thanks] Bye bye.

4 From Heritage (1984:267): "these terms [preferred, dispreferred] are not intended in any way to refer to the private desires, or psychological proclivities of speakers. On the contrary, we are here dealing with highly generalized and, as we shall see, institutionalized methods of speaking." From Atkinson and Drew (1979:59): "Thus the term 'preference' in this context does not refer to a speaker's psychological predisposition: instead it describes the systemic features of the design of turns in which certain alternative but non-equivalent actions are taken, as well as aspects of the sequential organization of such actions."

5 It should be noted that turn-taking practices, to some degree at least, differ by culture. E.g. Meyer, 2010; Mushin and Gardner, 2009; Philips,1976; Scollon and Wong-Scollon, 1990 have written about different organizations of the turn-taking system. Tannen $(1984,2012)$ should also be mentioned for her work on subcultural variation. Perhaps there are comparable differences in practices related to preference, as 
We see here that the interviewer employs a pre-request form that is recognizable to the recipient as such. (This is typical in the phone calls examined in their article.) The recipient responds, in lines 7--8, with a canonical form for rejecting requests, including a verbalized delay, an agreement form, and an account. Compare this to another call from the same paper:

(2) Maynard and Schaeffer (1997:53)

1. FR: Hello?

2. INT: .h tch Uh: hello: ma'am my name is Edward Price? a:n I'm

3. calling from the University of Wisconsin? as part of our national

4. public opinion study? .hh uh we're tryin to reach people: at

5. their home numbers (.) I[s this a residence ma'am? FR:

7. (1.4)

8. INT: <Don't hang up on me.>

Maynard and Schaeffer observe that, in contrast to their earlier examples, this is an example of an impolite response. The dispreference markers are used to produce politeness, and their absence expresses impoliteness. ${ }^{6}$

The point that I wish to make is that, on each occasion of invited response, recipients make a choice, a personal, motivated choice, as to whether and to what degree to be polite. Their preference, in a psychological sense, is the determinant of their manifest choice. Since dispreference markers produce politeness, their employment on each occasion is ultimately a result of personal psychology, that is, of individual choice. The fact that dispreference markers are usually deployed (if indeed they are) in cases of disagreement, rejection, and other uninvited responses, is a result of the fact that people usually choose to be polite.

So, what conversationalists in the aggregate do is based on the choices that they make as individuals, and CA is not equipped to investigate what produces those choices. (I agree with the stance, taken by just about everyone who works in CA, that it is no part of the job of CA to investigate the psychology of speakers' choices. ${ }^{7}$ ) Of course, we can still make statistical statements, if we have an adequate basis for quantification (more on this shortly), but, I would argue: (1) CA is not suited to quantification, i.e., it cannot usually produce defensible statistical results, and (2) To the extent that CA occupies itself with quantification and empirical generalization, it steps outside of its own unique methodological approach and its core concerns and into the realm of "normal" social science. But, if we are not to deal with the psychology of choice nor with the statistical outcomes of multiple choices, what are we to deal with? We can look at individual choices-in-context in terms of meanings expressed and relevancies

6 Interestingly, neither Schegloff (2007), in his chapter on preference, nor Pomerantz and Heritage (2012) mention the term politeness or its variants. Perhaps this is an example of the CA tendency to avoid terms (such as "speech act" and "implicature") that invoke other theoretical/ methodological approaches.

7 This "limitation" of CA, that it cannot deal with psychological matters, can be seen as a strong point. I have argued at length (Bilmes, 1986) on the desirability of a sociology 
and norms invoked, how each choice affects the local organization of that particular episode of talk. This does, as I will discuss in section 7 of this paper, lead to generalization, but not to statistical statements (including any claims regarding frequency) about what participants do.

In accordance with this understanding of $\mathrm{CA}$, I propose a modified perspective on preference: Preference retains its psychological sense. CA deals with expressions of preference, what we (claim to) want, or not want, explicitly or by implication. Dispreference markers are not what we produce under certain circumstances, defined by preference theory, but means of self-expression. Dispreference markers may mean something like, "I would rather not say this, but, for some reason, I feel that I have to." I emphasize that I am talking here about what speakers express, not what they may actually prefer.

\section{Preference as action}

My discussion so far has been based on the notion that preference theory, as it is currently presented in CA, is largely about participants' actions. In the middle (more or less) of his chapter on preference, Schegloff seems to take account of individual choice:

there is no shortage of dispreferred responses in talk-in-interaction. Every social setting is a world full of diverse interests and positions and turf and stances, all being managed (among other ways) in talk-in-interaction, and these are not suppressed or dominated by the organization of preference/dispreference (2007:72).

The important point here for my present purposes is Schegloff's focus on production of action. His view of preference, as the rest of his chapter bears out, is concerned with what participants do in conversation. A similar stress on production is to be found in Pomerantz and Heritage (2012). They propose that preference is constituted by a culturally shared set of "principles" of the form "If possible, do (or avoid) X." So, for example, "If possible, minimize stated rejections of requests," or "If possible, avoid or minimize a stated disagreement, disconfirmation, or rejection and, if possible, include an agreement, confirmation, acceptance or other supportive action." 8 The definition is entirely in terms of production.

8 "If possible," it would seem, has to be taken in a non-literal sense, indicating that one course of action should be favored over another, other things being equal. Also, we note once again the avoidance of cross-referencing other approaches to discourse. Pomerantz and Heritage's formulation is almost identical to Leech's "agreement maxim": "(a) Minimize disagreement between self and other; (b) Maximize agreement between self and other" (1983:132). 
With these two authoritative statements, I think it is safe to say that preference theory has been primarily about production and formatting of utterances and responses. Moreover, this conception of preference is basically probabilistic, although usually not subject to statistical analysis. This is especially evident in various statements by Pomerantz and Heritage (2012), such as the following:

“. . .there is considerable evidence to suggest that, in the context of yes-no questions, recipients generally orient to the principle of avoiding or minimizing disconfirmations in favor of confirmations. Questions ordinarily are designed so as to permit recipient confirmation, and recipients generally work to find ways of avoiding disconfirming responses and to build them with as many elements of confirmation as possible" (214, my emphases).

Schegloff (2007:63) writes that “. . . with considerable regularity (although clearly not invariably) responses to first pair parts deliver the preferred type of second pair part."

Returning to the quotation from Schegloff with which I began this section, the issue, I think, is not whether dispreferred responses occur. After all, Schegloff's discussion (and much of the literature on preference) is largely devoted to how such responses are formatted. The issue is whether preferred and dispreferred (i.e., invited and uninvited) responses always occur in the formats proposed by preference theory. My answer (and, judging from his mention of "diverse interests," Schegloff's as well) is that sometimes they do and sometimes they don't. What I wish to discuss below is the relation of these preferred/dispreferred formats to "other interests." First, however, we must consider the status of quantification in CA, since I have suggested that (a) the action-oriented approach to preference is inherently quantitative, and (b) that quantification is a matter with which CA is ill-equipped to deal.

\section{Quantification}

Schegloff (1993) and Zimmerman (1993, largely following Schegloff) suggest that quantification may be possible in CA, but their discussions make it seem very unlikely. Quantitative analysis is, Schegloff (1993:102) contends, "built on the back" of single case analysis. This means that we must analyze each case separately before including it in a count. And the outcome of such analysis (I would add) may itself be equivocal.

Suppose that we are counting answers to questions. We must first determine whether the prior to a candidate answer was indeed a question. This very matter is an issue in the following excerpt from the 1992 vice-presidential debate (Bilmes, 1999):

(3) 1992 debate (a) ( $\mathrm{Q}=$ Quayle, $\mathrm{G}=$ Gore, $\mathrm{M}=$ moderator $)$

1. $Q$ : $\quad$...the question is ' $n$ ' which you have $f:$ :ailed to

2. address and that is why is Bill Clinton (.5)

3. qualified to be president of the United States.

4. hh You've talked abo[ut Jimmy (.) you've=

5. G: [Oh l'll be happy to

6. answer (that question).

7. $\mathrm{Q}: \quad=$ talked about Jim Baker ...((deleted material))

8. you [haven't told us one=

9. G: Il'll be hapbv to answer (*) (.) Mav I answer 
11. Q: $=$ [reason why Bill Clinton (.) is qualified to be=

12. M: $\quad\left[\left(^{*}\right)(\right.$.$) The question (.) was your qualifications.$

13. Q: =president [of the United States

11. G: [l'll be happy- l'll be happy $\left[\left(^{*}\right)\right.$

12. Q:

13.

14. $\mathrm{G}$

wanna go back and make a point $().\left[\left(^{*}\right)\right.$

G:

[Well you've

15.

16. $Q$ :

asked me a question. $=$ Let me $\left[\left(^{*}\right)\right.$ won't answer my=

17. you a question l've made a statement.

18. G: =question I will answer yours.

19. ((audience laughter. $Q$ cuts in after about one

20. second))

21. Q: I have not asked a question I've made a statement

22. that you have not told us why Bill Clinton is

23. qualified (.5) to be president of the United

24. States.

If we are to count answers, in contrast to, say, "mere assertions," we must determine whether they respond to a prior utterance which is, for the participants, a question. As (3) demonstrates, this can be an issue, even for participants (see, in particular, lines 19--24). The same holds for other conversational acts, such as agreement with assessments. Before we can count instances of (dis)agreement, we must determine whether the prior to which the utterance to be counted responds is indeed an assessment. The nature of the prior may be (part of) what Schegloff means by the "environment of possible relevant occurrence" (1993:103), the "denominator."

The "numerator," "the set of types of occurrences whose presence should count as events" (Schegloff, 1993:103), presents similar difficulties. In the case of answers to questions, the issue is whether a particular instance is an instance of an answer. Again, from the 1992 debate: 
(4) 1992 debate (b)

1. G: ...wh:v has (.) Georae Bush waited

2. a half years, (.) during this health

3 . crisis, .hh before (.) finally coming out

4. proposal (.) just before the election

5. still: hasn't introduced it in Congress.

6. Iong wait, Dan. (2)

7. M: Mr. Vice President? (1)

8. Q: Al, (.8) President Bush has had his

9. reform: aqenda -on: C:apital Hill for

10 he's had parts of it up there for

11 you talk about increasing costs the

12 had on Capital Hill (.) medical

13 reform legislation for several years.

14 president's proposal deals with tax

15 deductions, and purchasing health

16 private sector, and making health

17 affordable and available to every

25 G: We still didn't get an answer to the

26 why George Bush waited for three

27 vea:rs=

$28 \mathrm{Q}:=\mathrm{He}$ didn't wait for [three and a half

$29 \mathrm{G}$ : $\quad$ [during the

$30 \mathrm{Q}:=$ =answer the question.

$31 \mathrm{G}:=$ health insurance crisis, before he

32 proposal (.) and it still hasn't been

33 Congress -in the form of legislation.

There is no issue here regarding the "denominator"---both Quayle and Gore recognize that a question has been asked. The issue here regards the "numerator"--did what Quayle said in response to Gore's question constitute (for the participants) an answer? Again, the same considerations apply to other sorts of speech action types. Before we can count occurrences of (dis)agreement, we must ascertain for each case that it is indeed, for the participants, an instance of (dis) agreement, rather than, say, a mere assertion.

These considerations are, in themselves, enough to cast serious doubt on the possibility of doing quantitative generalization in CA. Schegloff also mentions the problem of "domain." Different types of occasions (face-to-face "ordinary" conversation, interviews, telephone calls, courtroom talk, etc.) may affect the speech exchange systems involved in such a way that it makes no sense to generalize across these situations. I would extend this observation further: contexts such as argument may affect the way speakers construct their utterances. Thus, the claimed "preference for agreement" seems to be largely reversed when the interactants are 
arguing. Of course, we can just fold all these relevant contexts together and generalize across them, but, if we ignore the fact that there is clear variation by context, we have, in effect, lost the phenomenon. And, is there some finite number of possibly relevant contexts? If there is, how do we represent them proportionately? What proportion of our sample, for example, should be argument? And how do we consistently decide, for each instance, whether it is argument or something else?

Robinson (2007) recommends that conversation analysts attempting quantification try to minimize sampling error, but he does not say how this is to be accomplished. We can approach this problem by considering only very limited contexts (e.g., Clayman and Heritage, 2002). Or, we can solve it cleanly by considering the entire universe of generalization. So, for example, in two articles on the 1992 vice-presidential debate (Bilmes, 1999, 2001), I made various quantitative statements, but these applied only to what occurred in the debate itself; I was able to count every instance, so sampling was not an issue. When we come to the larger matters that are the usual subjects of CA generalization (e.g., the "preference for agreement"), the problems of contextualization and sampling seem insurmountable.

Schegloff allows that, "in some cases," quantification may be impossible in principle, while, in most other cases, it is "premature" (1993:114--115). However, he also states that

terminology such as occasionally or massively reports an experience or grasp of frequency, not a count; an account of an investigator's sense of frequency over the range or a research experience, not in a specifically bounded body of data; a characterization of distribution fully though tacitly informed by the analytic import of what is being characterized (119).

The "preference for agreement" may be a case in point. But, perhaps because of the types of contexts that were the primary object of study, conversation analysts were slow to realize that the "preference" did not seem to hold in the context of argument. And this, in turn, seems to suggest that the preference for agreement is not a matter of how conversation works but of what interactants are engaged in doing. Perhaps conversationalists do, numerically speaking, tend to agree. Does this observation advance our understanding or does it cast a fog that obscures crucial distinctions?

\section{Departures and exceptions}

\subsection{Compliments and self-deprecation}

Very early on it was noted that compliment responses deviated from the preference model, insofar as that model posited a preference for agreement (Pomerantz, 1978). This was explained by invoking a preference against self-praise, cross-cutting the preference for agreement. A similar diversion occurs in response to self-deprecation. It is disagreement with a self-deprecation which is preferred. However, this preference is again reversed (or at least, as Schegloff [2007:230] argues, neutralized) in the English language assessments analyzed by Lazaraton (1991, 1997), where language students offer self-denigrating assessments, which are not responded to with disagreement. 


\subsection{Accusations}

Atkinson and Drew (1979:60) observed that denials in response to accusations seem to be preferred, whereas confessions are dispreferred.

Speakers may exhibit the dispreferred character of actions which accept selfblame partly through their overwhelming use of the turn types which disavow blame ascriptions (i.e., denials, justifications, etc.) but also through their design of turns in which the dispreferred types occur.

There may be two sources of discomfort in this formulation. The first is the use of a statistical criterion. CA has no methodology for sampling. Although Schegloff (1993) argues for the possibility of rough, experientially based quantification, this is hardly rigorous. ${ }^{9}$ However, if we grant a tendency to prefer denial, etc. over confession, what is the explanation for this tendency? Is it not the individual preferences of the actors to avoid blame? ${ }^{10}$ Can we ground the tendency in social rather than psychological factors? This consideration, as well as the attraction of grounding all preference phenomena under a single social "motive," may have been what led Heritage (1984) to propose that denials, like other preferred responses, are the "socially solidary," "affiliative" alternative in that "an admission may announce a rift between the accused and others" (269).

Heritage is, in effect, making a distinction between what is invited (confession) and what is affiliative (denial). But the argument that denial in response to accusation is socially solidary seems particularly weak. Confession can lead to apology, a highly solidary act, whereas denial rules out apology. Confession to a crime may result in

\subsection{Agreement}

Atkinson and Drew's observations about the preferential formatting of denials date to 1979. In 1983, M.H. Goodwin published an article describing "aggravated correction and disagreement" in children's conversation. This was contrasted with adult procedures for dealing with disagreement. In 1988, Bilmes suggested, as part of a general discussion of preference theory, that, in the context of argument,

9 Atkinson and Drew do present a powerful argument for considering frequency of occurrence; namely, that it structures expectation. (I would add that it does this only it is insofar as it is known to the recipient.) We may design our utterances in accordance with the sort of responses that we expect. But, again, there are other factors which, in any particular case, may affect our expectations.

10 This actually seems to be implied in the following quotation from Atkinson and Drew (1979:112): "It was also mentioned that these second parts are not all equivalent, in the sense that some--those which avoid (deny or reduce) self-blame--are preferred on the part of the recipient, whilst others -- those which accept self-blame--are dispreferred". "Preferred on the part of the recipient" seems to invoke psychological factors. Incidentally, although I mention "avoiding blame" in the text, this is a commonsense example and not a proper part of a CA analysis. I do not think that CA needs to, or should, provide a motive, although it may discuss participants' motivational allusions. 
reduced sentencing. Even when it is believed, denial, unlike apology, is likely to be viewed as self-directed, avoiding blame. Although denial may be the most common response to accusation, and although it may be done in a format associated in many other contexts with invited responses, it is confession and not denial that is invited by accusation. (Accusations are assertions of a sort, and assertions invite agreement.) This demonstrates that the formatting of a response is not necessarily correlated with its status as invited or uninvited, nor is it determined by which response is "affiliative." There are other factors at play. Confession is invited and affiliative, but it is confession rather than denial which is frequently associated with dispreference markers.disagreement was frequently presented in preferred format and agreement in dispreferred format, and that failure to respond might be taken to implicate agreement (or at least lack of ability to disagree) rather than disagreement (see also Bilmes, 1995a, 1993, 1991). This "preference for disagreement" was supported by various other authors (e.g., Kotthoff, 1993; Gruber, 1998, 2001; Kakava, 2002) and now appears to be accepted widely within CA as an exception to the general preference for agreement. $^{11}$ (Bilmes (1995b) also found that, in a Thai negotiation, acceptance was done in dispreferred format, whereas rejections were done in preferred format.)

A recent dissertation by A.V. Drake (2013) claims that "or in turn-final placement relaxes the preference for a confirming response in that both disconfirmation and confirmation can be produced in a preferred manner without dispreferred turn design features" (II).

Exceptions will, it seems likely, continue to pile up and be walled off as special cases, until the exceptions become so numerous that the theory, in its present form, is seriously undermined.

\subsection{Other preferences}

My examples of exceptions to the preference model have all dealt with various manifestations of the purported preference for agreement. This is the widest ranging preference and the most discussed. I cannot say, at this point, whether other preferences, such as the supposed preference for grants of requests or acceptance of invitations, are similarly infirm. Perhaps they are more robust. Nevertheless, there will be departures, as illustrated in segment (2) above, according to variations in situation and personal interests and character.

\section{Untangling preference}

I would now like now to offer a respecification of preference theory as dealing with the production of meaning rather than action.

11 Lerner (1996), for example, states that "One common feature of all-out argument seems to be the structuring of disagreement within a preferred turn shape" (305). And Schegloff notes that 'the activity of 'arguing' or 'fighting,' as an activity in its own right, may have its own preferences and dispreferences" (2007:73). However, see Dersley and Wootton (2000) for an argument that the "preference for disagreement "in contexts of disagreement has been overextended. 
I would suggest that preference theory properly deals with the resources and constraints associated with the conventional expression of personal (psychological) preference. Note that I am not advocating that CA deal with the psychology of choice - it is the expression of preference that is at issue. Furthermore, we are dealing with the conventional expression of preference, as against what a hearer might suspect that the speaker really prefers. Preference theory, in my conception, is about meaning, its production and understanding. I will propose three, semi-independent aspects of preference: invited response, trouble markers, and first priority response.

\subsection{Invited response}

First pair parts generally "invite" (Pomerantz, 1984) a particular second pair part from a set of relevant second pair parts. Assertions invite acceptance or agreement, invitations invite acceptances, requests invite grants. This is their nature and their reason-for-being. ${ }^{12}$ Furthermore, Schegloff writes, "some preferences are grounded in the design of the turn embodying the first pair part" (2007:62). Compare "You're going to do that, aren't you?", with "You're not going to do that, are you?" Clearly, the two are oriented toward opposite responses. I think, though, that there is an important distinction to be made between responses aligned to prior speech acts and those aligned to prior turn design. Specific speech acts may invite specific responses. To say that an utterance invites a particular response is to say that it has conventionally expressed a desire that the interlocutor produce that response. On the other hand, turn design may have more to do with expectation than invitation. (Consider, for instance, an utterance such as "You're not going to help me, are you?"). ${ }^{13}$

\footnotetext{
12 Schegloff does not actually refer to invited responses as such. Rather, he speaks of "the character of the course of action, and the directionality of its trajectory toward realization of 'success"' (2007:62--63). As far as I can make out, though, this is another way of talking about invited responses.
}

13 This raises the question of invented data, a subject for another paper. Meanwhile, I rely on the assumption that the reader finds my invention plausible. 


\subsection{Response design: trouble markers}

Preference theory also deals with the design of responses to first pair parts that express preference. In terms of the formulation proposed here, whereas first pair parts (conventionally) express the preference or expectation of the speaker, the design of the second pair part expresses the supposed preference of the recipient. (Note that this is a very different way of talking about the matter from that of orthodox preference theory.) Speakers are said, first of all, to use various techniques to avoid dispreferred responses. This, as I have already suggested, is a matter of choice. Conversationalists will avoid "dispreferred" (e.g., impolite) responses when they prefer (in the psychological sense) to do so. Perhaps they usually do so, but that is a statistical claim, making selectivity in the collection and presentation of examples an issue.

When, for whatever reason, a dispreferred response is produced, it is likely to be accompanied by "dispreference markers," expressing reluctance to be impolite or unobliging. The main markers of dispreference are delays, mitigations, and accounts. I will be interested in particular in delays.

Sacks (1987 [1973]) noted that disagreeing responses tend to be pushed back in the turn, by pauses, filled pauses (e.g., "well"), or preliminary expressions of agreement (these are sometimes dealt with as mitigations rather than delays). I have, in the past, referred to delays, which are treated as markers of dispreference, as "reluctance markers" (Bilmes, 1988). This makes for a certain clarity as well as economy. Clarity because it indicates exactly what is being expressed by delay -- a reluctance to say whatever follows. Economy because it simplifies the usual formulation in preference theory. That formulation is that delays (in certain sequential positions) normally portend dispreferred responses. However, when they precede preferred responses, as they sometimes do, they suggest that the response is somehow problematic. It is simpler to say that delay expresses reluctance to produce whatever response follows, whether that response is invited or not. 14

But "reluctance" is too narrow. A better term might be "trouble markers," because delays do not always indicate reluctance. Delay in responding may be due, first, to mechanical or environmental problems -- the respondent stutters, or has something caught in his ${ }^{15}$ throat, or is waiting for background noise to subside, etc. Second, the respondent may have a problem in understanding or processing the previous utterance, or perhaps has not recognized that it calls for a response. Third, the respondent can't think of what to say, or requires time, say, to check his calendar. Fourth, the respondent knows the content of what he wants to say, but is trying to find the right phrasing. Fifth, the respondent has formulated his utterance but is, for some reason, reluctant to produce it, or at least wants to demonstrate reluctance.

14 This, as well as other features of the turn-taking system, is, as already noted in footnote 5 , culturally sensitive.

15 Since I find dual gender reference stylistically awkward, I have chosen to follow the convention that the general pronoun accords with the sex of the writer. 
(I have left out of this account "dramatic pauses," which are not trouble markers at all.) Only the fifth and perhaps the fourth cases are dealt with in preference theory. If a delay were thought, by the original speaker, to be caused by any of the first three items listed above, it would not usually portend either a preferred or dispreferred response. Delays of the fifth type (and perhaps the fourth) are most properly referred to as "reluctance markers." Of course, in practice, the hearer must decide what sort of delay he is hearing.

Whereas we cannot always be certain what caused a delay, absence of delay is more readily interpretable. Heritage (1984:268) notes that "An 'early' or unmitigated [dispreferred] response can easily be heard as 'hostile' or 'rude"'. Clearly, the usual delay is doing something more than merely portending a dispreferred response. If that were the case, all we could say about an undelayed dispreferred response is that the respondent made it without first giving a clue that it was coming. The reason that the undelayed dispreferred is rude is that the respondent is signaling that he is not reluctant to offer such a response. This also handles the matter of denials (in "preferred format") in response to accusations. The respondent simply produces a response without the usual trappings of politeness: he expresses no reluctance in contradicting the accusation. This is not surprising. Other, personal interests are commonly recognized to be at stake. And, of course, the prior accusation is already a breach of politeness. Again, it is not CA's job to supply motives, even when, as in this case, they may be obvious. A general tendency toward social solidarity might be admissible as a principle of conversational organization, but, as I have argued, it hardly seems applicable in this case. Instead, it appears that other, personal considerations overwhelm any hypothesized tendency toward socially solidary response.

\subsection{First priority response}

What is implicated if the respondent fails to respond to an accusation? We might read this as failure to deny. This is not a matter of what response is invited, since confession is the invited response. Rather, it is a result of our judgment that the respondent would prefer to deny if only he could. This is a matter of judgment and interpretation, and, in this case at least, commonsense psychology, rather than some theoretical characteristic of conversational organization.

We should note here a difference between silence and hearable delay. ${ }^{16}$ By "hearable delay," I mean that the respondent prefaces his response with "well" or "uh" or an inbreath or some other preliminary that indicates a response-to-come. Consider, for example, responses to non-accusatory attributions. If I make, in your presence, some attribution concerning your attitudes or behavior, and you do not contradict, you have allowed the attribution to stand, even if you have not explicitly confirmed it (Bilmes, 1988). Silence here implicates acceptance. On the other hand, if, upon my producing the attribution, you do a hearable delay, I may expect some form of contradiction (on the assumption that you are being polite and are reluctant to

16 The fastest and most efficient way to produce a relevant silence is to change the subject. A delay may consist of no talk, whereas a silence may be filled with talk, and, in a sense, consist of that very talk (Bilmes, 1994). 
contradict).

Contradiction in response to an attribution is what I have termed a "first priority response." I have formulated first priority response as follows: "If $X$ is the first priority response, then any response other than $X$ (including no response) implicates (when it does not explicitly assert) that $X$ is not available or is not in effect, unless there is reason to suppose that it has been withheld" (Bilmes, 1993:391; see also Bilmes, 1995a, 2012). ${ }^{17}$ Frequently (given my comments on quantification, I will refrain from saying "normally"), the first priority response to, say, an invitation is acceptance. If acceptance is absent, then we are likely to understand that the invitation is not accepted. This is so even though rejection is also absent. That is, it is acceptance, the first priority response, that is relevantly missing. Another aspect of first priority response relates to items arranged in series according to strength or intensity. It is generally understood that the strongest, most intense, or most extreme item that applies will be mentioned. In other words, the most extreme item gets priority mention. If, for example, excuses $A, B$, and $C$ are progressively stronger, it is understood that one will offer $C$ if one can, even though $A$ and $B$ may also be true. If one offers $B$, it will be understood that $C$ is not available, that $B$ is the best one can do. Note, though, that, whereas there may be various groundings for first priority response, the concept itself is simple: If a first priority response is not present, then it is noticeably absent and presumed unavailable. Conversely, if its absence will be notable, then it is the first priority response.

\subsection{Accusations reconsidered}

We will examine an accusation sequence from data that I collected in a Northern Thai village. Although various aspects of the context are culturally specific, it appears to me that accusation sequences work the same in Thai as they do in English. The setting is a rice field. Kææw, the sharecropper, and his wife, Dææng, are negotiating with Dii, the owner, regarding how the rice is to be divided. Also present are Muun, the former village headman, who moves in and out of the role of mediator (Bilmes, 1992), two villagers, my field assistant (a university graduate from a different village) and myself. Kææw is demanding more than the traditional share because Dii has informed him that this will be his last year as sharecropper. (Dii is planning to have his nephew work the fields.) I have chosen to examine this sequence because it is unequivocally an accusation sequence, and because I think it has certain especially interesting aspects.

17 In the 1993 article, I explained how response priority differs from Gricean implicature. I would add that it is also broader than Drew's concept of maximization, in that it applies to cases such as the choice between denial and confession. I went on to develop the concept in such a way as to comprise maximization, although I did not credit Drew, whose work on the subject $(1985,1992)$ I had not read at the time. 
(5) Rice division (a) ${ }^{18}$

1. Dææng: You said

2. Dii: I (.) told you [nicely.=

3. Dææng: [(get rid of us)

4. Dii: =You didn't listen. You really! you ran to the kamnan ((a

5. local official)).

6. Dææng: Yeah, but you [said $\left(^{* * * * *)}\right.$

7. Kææw: [You told me (.) right? (.8)

8. Dii(?): ${ }^{\circ} \mathrm{mhm}{ }^{\circ}$

9. Kææw: What did we agree to? (.8) What did you say to me?

10. (.8) I asked (.) what do you want me to do? (.8) I ((Dii)) want

11. you to work permanently (.5) Do it until you're bored with it.

12. (.5)

13. Dii: I didn't [say that (.) I didn't say that (.8) didn't say that.

14. Kææw: [As long as you're not bored (1) as long as you're

15. not bored (.8) how can the owner take it away from you (.)

16. didn't say $\left({ }^{*}\right)$ You said it in (that field).

I will first work through some of the important elements of this exchange to clarify what is going on. Roughly, what we have here is accusation---denial---insistence. The accusation is complex, beginning in line 7 and carrying through to line 11 . The length and complexity is produced in part by the ambiguity of Kææw's initial question (line 7--"You told me, right?"). Although Kææw invites a positive response with "right", it is not clear that Dii would know how to answer, since Kææw has not yet specified what it is that Dii supposedly told him. (It cannot be read as referring to what Dææng says in line 6 , since it overlaps that line.) There is a .8 second pause (followed by an ambiguous grunt, which may or may not have been produced by Dii), and Kææw follows up with a second question (line 9---"What did we agree to?"). This time, it is clear that Kææw is asking about their agreement regarding sharecropping arrangements, but, once again, there is a .8 second pause, followed by yet another question (line 9---"What did you say to me?") and, yet again, a .8 second pause. Kææw has made multiple, unsuccessful efforts to engage Dii. ${ }^{19}$ Finally, in lines $10--11$, Kææw answers his own questions. ("I asked (.) what do you want me to do? (.8) I ((Dii)) want you to work permanently (.5) Do it until you're bored with it.") Rather than simply saying what Dii

18 I use an asterisk in parenthesis to indicate about $.5 \mathrm{~s}$ of untranscribable speech. I place pauses immediately after the talk which they follow, rather than putting some on a new line, as a way of avoiding pre-analysis. Punctuation is for clarification of meaning only and does not indicate intonation. (Northern Thai [Kammang] is a tonal language, and intonation, if it can be said to be present at all, works differently than it does in non- tonal languages.) In all other respects, I follow standard CA transcription conventions. See Appendix for Northern Thai transcription.

19 Perhaps the provision of a second pair-part is more optional when it is clear that the 
supposedly said to him, he places Dii's talk in an interactional context, as the response to a question that Kææw had asked. This may increase the credibility of Kææw's claim by showing why Dii said what he (purportedly) did, i.e., why he spoke to that topic.

The pause after "What do you want me to do?" (line 10) may be a signal that the next part of the utterance is an unattributed quote. It is common in villager discourse to use direct quotations without explicitly marking them as such (Bilmes, 2009).

The relevant context is that Dii is ending their sharecropping arrangement, which means (if Kææw's account is accurate) that Dii is breaking his promise. Breaking a promise is a "bad" thing. An accusation is an assertion that someone has done a thing which is known to be bad (Langendoen, 1971). Kææw's tone of voice (including but not limited to loudness), supports the interpretation of his utterances as constituting an accusation.

After two .5 s pauses, in lines 11 and 12, Dii finally denies Kææw's accusation. (line 13-"I didn't say that (.) I didn't say that (.8) didn't say that.") The first appropriate place for such a denial to occur is immediately after Kææw's claim that Dii asked him to work permanently, since this constitutes the broken promise. The second is after the augmented accusation in line 11. His denial, although delayed, is unequivocal and vigorous, so the signals are mixed as to whether he finds the denial problematic. Kaew overlaps on the third word, the denial being projectable. His contradiction takes the form of insistence (through repetition) on what he just said. (lines 14--16---"As long as you're not bored (1) as long as you're not bored (.8) how can the owner take it away from you (.) didn't say (*) You said it in (that field).") He points out that the owner said that he cannot take the work away from the sharecropper, which is a matter of tradition. (This is only partly true, since owners may terminate a sharecropper who is not doing a satisfactory job.)

An accusation makes a limited number of response types conditionally relevant, and one of these is denial. And the occurrence of a denial supports the claim that the responder heard the prior utterance as an accusation. Of course, there is a possible circularity in that the hearing of the response as a denial may be contingent on hearing the prior as an accusation. Do Dii's pauses express a reluctance to disagree? This seems unlikely, given that he is being accused of breaking a promise and that his action (terminating Kææw as sharecropper) has already been decided. If anything, the pauses would point to some problem in producing the denial, for example, uncertainty or insincerity, although this interpretation, as has been noted, is contradicted by Dii's eventual delivery. Dii's defense is, at the same time, both unequivocal and weaker than it could be.

In line 16, we find "didn't say (*)". This seems to signify something on the order of "what do you mean you didn't say that?" Then Kææw locates where the statement occurred (line 16---"You said it in (that field)."). Locating it in a particular place reinforces Kææw's credibility by demonstrating (or rather claiming) a detailed memory. The exchange continues: 
(6) Rice division (b)

17. ?: $\left({ }^{*}\right)$

18. Dii: Speak $\left[\left(^{*}\right)\right.$

19. ?: Speak $\left[\left(^{*}\right)\right.$

20. Kææw: $\left({ }^{*}\right)$ said it there.

21. Dii: Don't speak strongly. We should be embarrassed in front

22. of him/them. ((No doubt referring to me and perhaps to my

23. field assistant.))

24. Kææw: Oh:::: (.5) If I have anything to say, I say it.

25. Dææng: (Let's) discuss it further, okay?

Kææw continues to insist on his version of events in line 20 ("said it there."). Dii, instead of pursuing his denial picks up on another element of the talk---its tone. He probably attempts to begin his objection in line 18 ("Speak (*)"). In lines 21--22, he interrupts the flow of the talk to do a sort of metacommentary ("Don't speak strongly. We should be embarrassed in front of him/them."). ${ }^{20}$ This sort of commentary, it would seem, is generally available in conversation as a resource for diverting the topic. Dii's move seems relevant and legitimate, but fails to reinforce his denial in the face of Kææw's insistence. Kææw, in line 24, rejects Dii's admonition ("Oh:.:.: (.5) If I have anything to say, I say it."), but Dææng (line 25--- ("Let's) discuss it further, okay?") seems to take a somewhat more conciliatory stance (in relation to tone, not necessarily content.). Continuing further:

(7) Rice division (c)

26. Dii: You y-you asked to work asked me at my house to work.

27. Kææw: Of course (.5) I asked to work your fields (.) If you

28. didn't agree to let me work your fields how could I do it (1)

29. right?

30. Dææng: $\left(^{* * *}\right)$

31. Kææw: Yeah, and you even asked me at that time (.5) how

32. much rice are you harvesting on sister Can's fields? ((Kææw

33. worked Can's fields before going over to Dii.)) (.8) Getting

34. that much you won't have enough to eat. Did you say it or

35. not? (1.5) [Did you say it? (.5) [Did you say those words? (2)

36. ?:

$\left[\left({ }^{*}\right)\right.$

37. ?:

38. Dii: I said $\left[{ }^{* * *}\right)$

39. Muun: [Let's do it like this (.) [I say $\left(^{*}\right)$

40. Kææw: [What do you mean you

20 Lines 21--22 also, of course, raises some interesting issues regarding fieldwork and data collection, but this is not the place for that discussion. 
41. didn't say it? We spoke in the field, Father Dii. (.) I didn't

42. forget.

43. Dii: Udo[m ((Dii's niece)) (.) Udom was the one who=

44. Kææw: [l'm not old.

In line 26, Dii presents himself as having done Kææw a favor ("You y- you asked to work asked me at my house to work."). Kææw first minimizes his request to work Dii's fields by portraying it as routine and necessary (lines 27--29---"Of course (.5) I asked to work your fields (.) If you didn't agree to let me work your fields how could I do it (1) right?."). Then Kææw turns the tables by suggesting, in lines 31--35, that Dii invited him to work his fields ("Yeah, and you even asked me at that time (.5) how much rice are you harvesting on sister Can's fields? (.8) Getting that much you won't have enough to eat. Did you say it or not? (1.5) Did you say it? (.5) Did you say those words?"). There is some delicate moral positioning going on here. He finishes by once again challenging Dii to remember his own words. Once again, there are multiple pauses before Dii responds. These pauses may be contrasted with Kææw's contradictions, which are largely done in overlap. Apparently, in line 38, Dii denies having encouraged Kææw to sharecrop his fields, at least in the way that Kææw claims ("I said $\left(^{* * *}\right)$ "). Most of line 38 is untranscribable, but Kææw's lines 40--42 ("What do you mean you didn't say it? We spoke in the field, Father Dii. (.) I didn't forget.") seem to indicate the general nature of what Dii said. Muun's attempt to intervene (line 39---"Let's do it like this (.) [I say $\left({ }^{*}\right)$ "), apparently with the aim of offering some solution, is cut off by Kææw's insistence on the accuracy of his description, in the course of which he, once again, specifies the location where Dii purportedly spoke (lines 40--42). Although age is respected in Thailand, Kææw uses it here (lines 42--44--- “I didn't forget. . .I'm not old") to belittle Dii and legitimate his own version of what occurred.

Here is the conclusion of this exchange:

(8) Rice division (d)

43. Dii: Udo[m ((Dii's niece)) (.) Udom was the one who=

44. Kææw: [l'm not old.

45. Dii: =encouraged you to come and work here. (1.5)

46. Dææng: Right, Udom was the one who [encouraged us.

47. Kææw:

48. ? [Yeah [(.) Udom= $\left[\left({ }^{* *}\right)\right.$

49. Kææw: =encouraged (.) [us.

50. Dææng:

[And it's it's not Udom's prop[erty. It's=

51. Dii: [And now =

52. Dææng: $=$ [yours.

53. Dii; $=[$ it- it's like this

54. Dææng: If [you didn't allow us to work, we wouldn't be able to=

55. Kææw: [Yeah.

56. Dææng: =work. You [agreed to let us work and we already=

57. ?:

58. Dææng: =settled it.

59. Kææw: I do(h)n't kn(h)ow whose fault it $(h) w(h)$ as hehhaha 60.

I'm not criticizing anyone hahaha.= 
Dii, in lines 43--45 ("Udom ((Dii's niece)) (.) Udom was the one who encouraged you to come and work here."), admits that Kææw was encouraged to sharecrop Dii's fields, but attributes this to his niece, Udom. Dææng (line 46---"Right, Udom was the one who encouraged us.") agrees, but only after a 1.5 second pause. This might be read as reluctant agreement, especially given her continuation in lines 50--58 ("And it's it's not Udom's property. It's yours. If you didn't allow us to work, we wouldn't be able to work. You agreed to let us work and we already settled it."). Kææw (lines 47--49---"Yeah (.) Udom encouraged (.) us.") also accepts Dii's attribution. In his case, this acceptance may be preliminary to his conciliatory stance in lines 59--60. At any rate, they have not abandoned their position, but, by allowing Udom into the conversation, they seem to have softened their tone. Then, in lines 59--60 ("I do(h)n't kn(h)ow whose fault it (h)w(h)as hehhaha I'm not criticizing anyone hahaha."), Kææw goes further and makes the transparently false statement (note the laugh tokens) that he is not criticizing anyone. The denial of anger is perhaps more common in Thailand than in Western cultures, since a declaration of anger is itself an angry act and may lead to a rupture of the relationship.

Thus, there are, broadly speaking, two accusations leveled against Dii: (1) He broke a promise, and a traditional obligation, to let Kææw sharecrop the land for as long as he (Kææw) was inclined to do so. (2) He encouraged Kææw to drop his previous arrangement with another landowner and sharecrop his (Dii's) fields instead. Although Kææw is quite adamant on both points, he, in concert with Dææng, allows Dii to divert the blame for (2) to Dii's niece. It is especially notable that, although each accusation is met with a denial by Dii, when Kææw insists on the validity of his accusation, Dii does not pursue his denial. Instead, in the first case, he comments on the tone of Kææw's talk, and, in the second, he attributes the act in question to his niece.

I played this tape for a villager, a key informant. He commented, "At least they didn't reach khing and haa." Khing (you) and haa (I, me) are disrespectful pronouns. Older, higher status villagers regularly refer to younger ones with these pronouns, but it would have been a major breach of etiquette for Kææw to use them with Dii. Instead, he refers to Dii throughout as Phøø (father) Nøøy (honorific for one who has served as a Buddhist novice). This preserves a veneer of politeness and the possibility that they will, as the villagers say, "be able to look each in the face" when this is over.

Now, let us examine this exchange in terms of the three features of preference that I suggested earlier. First, Kææw is clearly inviting Dii to admit that he made the attributed promises. Such an admission would, in Schegloff's terms, permit the projected trajectory of the interaction to proceed uninterrupted. Presumably, Kææw would have proceeded to make his case for a division of the rice that was more favorable to him. Instead, Kææw has to deal with Dii's denial. It would seem very odd to claim that Dii's denial was the socially solidary alternative. Solidary with whom? Kææw certainly doesn't seem to find it so.

The canonical denial should, according to preference theory, occur in preferred format, that is, without pause or other dispreference markers, since denials are, supposedly, preferred. However, Dii's denials are preceded by multiple pauses, and so marked for dispreference. These pauses suggest that the eventual denial is somehow troubled. Indeed, although at least the first denial is vigorously 
presented, ${ }^{21}$ it is not pursued in the face of Kææw's immediate contradictions. The first denial is diverted into an admonition not to speak strongly. The second is not absolute; instead of claiming that the attributed action did not occur, there is a shifting of blame to Dii's niece. So, we have here two species of denial --"I didn't say it (and it never occurred)" and "I didn't say it (she said it)". (However, Kææw's insistence, in segment (7), that Dii encouraged them is quite strong and is never explicitly withdrawn.) Whereas admission is the invited response, denial is the first priority response, in that absence of denial would be tantamount to admission.

What actually occurs in this exchange is somewhat equivocal. Dii denies, in line 13, that he offered Kææw permanent tenure. In line 38, he apparently denies that he encouraged them to sharecrop his fields. In both cases, Kææw immediately contradicts. In the first case, Dii changes the subject rather than pursue his denial. In the second case, it is Kææw who, in part, abandons his accusation by accepting that Udom had encouraged them. However, Kææw does not quite withdraw his assertion that Dii encouraged them. And Dææng and Kææw insist on Dii's responsibility regardless of who encouraged them. The first denial is particularly interesting, since it is marked both for strength (repetition and unequivocal wording) and for weakness (delay and failure to follow up). Preference theory has dealt very largely with either troubled or untroubled presentation, but the signals here are mixed.

Kææw's responses to Dii's first denial and, initially, to his second, are not aimed at minimizing disagreement, as preference theory might predict. This is more the sort of interaction that has been found to characterize argument. Kææw would rather be right than polite--this at least, is what is expressed by his action.

The exchange in segment (8), centered on Udom's alleged role, is similarly complex. In this case, Dææng and Kææw produce the invited response, namely, agreement that Udom encouraged them to sharecrop Dii's fields. However, their agreement is delayed. For Dææng, it appears, agreement is reluctant. For Kææw, it may be part of a conciliatory move.

I am not concerned here with what Northern Thai speakers usually do or with their supposed efforts to achieve an interaction approximating the prescribed preference model. My point is not that accusers and deniers do things this way or that way, but that however they do it on any particular occasion can be examined for the meanings expressed. I am suggesting that we retreat from empirical generalization back into the indexical particulars of the situation. Does this "retreat" leave an opportunity for findings of a general nature? I believe that it does, but the findings concern methods of meaning production and interpretation, as discussed in section 7.

In summary, we can re-examine responses to accusations in terms of the three notions of invited response, trouble markers, and response priority. First, we note that confession is the invited response. Second, that denial is the first priority response; that is, if a denial is not forthcoming, it will be noticed as relevantly absent, with an implicated acknowledgment of guilt. Finally, the occurrence of reluctance markers

21 Might we say that features such as vigorous and unequivocal presentation are "preference markers"? 
suggests that the impending response is in some sense troubled. If it is a confession, the source of the trouble is ordinarily obvious - the respondent is reluctant to confess. If it is a denial, the sincerity or some other aspect of the denial may be brought into question. We must also consider, however, the tone of the denial itself. What are we to make of a strong but trouble-marked denial? In any case, for participants, the specific interpretation of trouble markers is a matter of judgment, based usually in commonsense psychology. I offer this way of dealing with "preference" as an alternative to saying that agreement is preferred, except in response to accusations or compliments or self-denigration or in the context of argument, and so forth.

Orthodox preference theory, I would argue, is not really, or at least entirely, a theory of how conversation works -- it is rather a prediction of how people will behave, an attempt at empirical, statistical generalization. It is true that the generalizations made in the literature on preference are supported by numerous examples, but they are selected examples and so lack statistical validity. The claim seems to be that preference theory (the action-oriented variety) holds for an overwhelming number of cases (Schegloff, 1993), but this may be, in part, an artifact of the sorts of conversations that have usually been analyzed. I am not sure what is gained analytically by statements, even accurate statements, about the statistical predominance of a particular sort of response or action, statements which gloss over the particular circumstances of production and reception.

It is a familiar observation that initially promising theories in social science break down as more contexts are brought under consideration. Thus, for example, the move from an essentialist to a situational approach in psychology (Howard, 1982). Perhaps something similar is happening, or will happen, or should happen with preference theory. 22

22 This is as good a place as any to mention that this paper originally had two sections that I removed for structural reasons. One dealt with preference as applied to first pair parts. I noted that, in addition to problems already mentioned in connection with second pair part preference, there are three further complications. One is that our inventory of speech acts is vernacular and so a questionable basis for analysis, especially when we consider that different languages may have different lists. The second is that choices made in regard to first pair parts are content-sensitive. Finally, speech actions may be ambiguous; in saying that " $X$ is preferred over $Y$," we have made a useful (or at least meaningful) statement only if instances of $X$ and $Y$ can be unproblematically identified. The second deleted section dealt with what might be called "the preference for preference." It suggests that there has been a bias toward interpreting certain conversational phenomena as preference-related when there are other available interpretations that are equally or more convincing. When you have a hammer, it is said, everything looks like a nail. 


\section{The conversation analytic endeavor}

Here is a segment first presented by Sacks (1987:62 [1973]) and used by Schegloff (2007) and Pomerantz and Heritage (2012) in their discussions of preference.

\section{(9) Sacks (1987)}

A: That where you live? Florida?

B: That's where I was born.

This is offered as an example of the preference for agreement, or the dispreference for disagreement. ${ }^{23}$ (Schegloff comments that it is "clear" that B does not live in Florida. Sacks says it is "obvious." Neither elucidates this observation, which would, I suppose, lead to a discussion of implicature.) But what is the actual significance of this example? Surely, a disconfirming answer, such as "No, I live in California," could occur. ${ }^{24}$ And, if it did, what would that prove? Could I use it as an example of a claimed preference for disagreement? In either case, we are dealing with selected examples. One response to this objection might be that (9) is not offered as evidence for the preference for agreement; rather, it is a demonstration of one way that such a preference is realized. But, if examples such as (9) are not evidence for such a preference, where is the evidence?

I would like to argue that examples such as (9) are significant, that they, in fact, are proof of a sort. My argument is that the concepts of evidence and proof have a particular interpretation within CA. Popper (1959) suggested the falsification criterion for scientific laws. A scientific "law" is true until further notice. At any moment, an event may occur which stands in contradiction to the "law," at which point it is no longer a law. There is no way to prove a scientific law to be true. All we can do is to repeatedly test it and fail to disconfirm it. Such a conception of scientific truth clearly has no application within social science, which does not deal in laws. The dominant criteria governing generalization in most social science have been correlation and probability. Statistical analysis has been the ultimate measure. (It is true that there is a great deal of descriptive and interpretive work in social science, but this work does not seem to offer any criteria to govern generalization.) CA, I would argue, does not rest on a probabilistic base, and its notion of evidence and proof is more or less the obverse of Popper's.

The claim that CA is not a probabilistic undertaking is rooted, on the one hand, in the lack of a sampling methodology and, on the other, in the nature of the CA endeavor.

23 It is notable that in none of the presentations of this example are we given the talk that led to this point and that may have made B's reply relevant aside from any predilection to agree. For the sake of discussion, I will put this objection aside.

24 Once again, I use invented data and rely on a native's sense of what is plausible. 
Even the weak assertion that CA sometimes permits statistical generalization by virtue of overwhelming experience (Schegloff, 1993) may be undermined by consideration of previously unexamined or underexamined contexts.

The CA handling of evidence, as I have said, is more or less the obverse of Popper's. Each intelligibly occurring item is, in a real sense, its own proof. It proves that this is one way that a certain meaning or a certain conversational sequence can be achieved. This is a possible member's practice. Sacks (1992:256--257) observes that children commonly make room for themselves in conversation by beginning with "You know what?" But even if this were not a common practice, even if Sacks had only found one case, the analysis would stand.

A "CA claim," in my usage, is a claim about the resources available to interactants in constructing meaning and enabling or constraining conversational organization and conversational outcomes. CA makes statements such as, "This is a way to perform action $X$ or achieve meaning $Y$ or affect the trajectory of the conversation." CA is about How, about method. How is a certain meaning produced? How is an utterance interpreted? How is conversational organization achieved and manipulated? Of course, it is possible to misconstrue or fail to see the significance of an occurrence. Falsification occurs in CA only through reinterpretation, not hypothesis testing. One cannot disprove a CA phenomenon by finding instances in which the phenomenon does not occur.

Take the example of questions. A very strong generalization in CA is that questions call for answers. But sometimes questions do not receive answers. In such cases, it is common for the respondent to account for the failure to answer. This accords with the normative expectation. It sometimes happens, though, that questions are not answered and no account is offered. In such a "deviant" case, the questioner may repeat the question or, in some way, sanction the recipient, or at least note the absence of an answer. Such practices, far from negating the notion of a normative requirement for answers to questions, support it. However, it may also happen that a question does not receive an answer or an account for not answering, and that this is let pass without sanction or explicit notice. The fact that this may and does happen does not disprove the existence of normative expectations regarding questions and answers. Rather, the fact that sanctions do sometimes occur proves the existence of the norms. So, CA can generalize in terms of norms (as guides to interpretation and justification for action) rather than statistical statements about behavioral outcomes.

In the case of preference, I think the appropriate move is to convert statements about what people usually do, statements which are subject to falsification through counting (if only we had a valid method for sampling), to statements about how they convey meaning. If we can find even one example of a meaning being intelligibly conveyed using a certain method, then we can say that this method (under given circumstances) is a way of conveying this meaning. So, when we are speaking of preference, a relevant question is: How do speakers express their personal preferences in the course of producing their conversational actions? (Again, this is a matter of expression, not of the speaker's actual psychological state.) 
What we can properly say about segment (9) is that, if one wants to implicate disagreement without expressing it directly, B's response is one way to do it. Instead of a "preference principle" such as "If possible, avoid or minimize explicitly stated disconfirmations in favor of confirmations," I would suggest, (a) if you want to be polite, avoid or minimize stated disconfirmations, and (b) here is a way that one can achieve avoidance or minimization. Or, perhaps better: if you want to avoid or minimize explicitly stated disagreement for whatever reason, here is a way to do it. That is, statements about preference should be reformulated as statements about possible choice and actions to achieve that choice.

In this conception, CA is not about production of certain classes of utterance or response. It is about techniques for constructing and interpreting meaning, and producing and constraining conversational organization. It is about the resources provided to participants for the construction of such meaning and organization. These resources can be very particular or very broad. Take Sacks' observation that offering one's name puts pressure on the recipient to offer his own name. This practice has broad application but also is part of a larger conversational phenomenon reciprocity. The tendency to provide "second stories," as well as various other sorts of seconds, is also based in reciprocity. This provides for a strategic move; if you can get the recipient to provide a first story of a certain type, then you have created a slot for your own second story. In a transcript of a phone-pal call to China from America, the American asks the Chinese to describe where she lives. This shows an appropriate interest in the other. At the same time, the American gets a slot, which she proceeds to use, for describing her own surroundings. To raise this as a first rather than as a reciprocal second could be awkward, assuming as it does that the other cares.

In this final example, from the Linda Tripp/Monica Lewinsky tapes, Lewinsky brings up the subject of her own upbringing by showing an interest in Tripp's upbringing and then reciprocating.

(10) Tripp/Lewinski, Tape 6

1. Lewinsky: Wull- I mean I would just that's just- for me: ya know

2. that's just how: (1.5)

3. Tripp: I mean: [(.) I have (this)

4. L: $\quad[(a n ')$ l'm sure you were raised too in a very: (.) sort of

5. 5. honorable: $(.5)\left[\left({ }^{* *}\right)\right.$

6. T: $\quad$ [I would have b- I would have probably been: (.5)

7. $\quad[$ tarred $=$

8. L: $\left[\left(^{*}\right)\right.$

9. $\mathrm{T:}$ : =and feathered (.) if I even considered saying something like 

10. that in my house. $=$
11. L: =Right $().\left[\left(^{*}\right)\right.$ an' I'm- an' I was brought up with lies.=
12. T: $\quad[($ look $)$
13. L: $\quad=($.$) all (.) the time. (.5) So tha- that was how: (.) that was$
14. how: you got along -in life -was by lying.

The point of all this is to suggest that there are large and interesting generalizations to be made within CA, even when we eliminate attempts at statements about how conversationalists usually behave. CA, from my perspective, is about ethnomethods (Garfinkel, 1967). It is about how we construct, through practices of production and interpretation, a stable, comprehensible social order and a particular understanding of what is going on in our social lives.

In this paper, I have attempted to codify, to some extent, my sense of what CA is as an analytic endeavor. My approach is not "realistic." That is, I do not take the view that $\mathrm{CA}$ is whatever conversational analysts do. I take the more Platonic view that CA has a basic nature, that CA is essentially a way of elucidating the resources that members have available to them, and the constraints they face, in the production, interpretation, and organization of meaning. I am not proposing something new; I am merely trying to clarify. The concepts and methods that I am advocating are already CA concepts and methods. When I first encountered CA in the early 1970s, it opened for me not only a new way of working but a new way of understanding. It had its own, unique intellectual esthetic, its own vision. I am not suggesting that CA once possessed and now has lost some primal "purity." But we can continually push toward a clearer understanding of the essence of the conversation analytic endeavor. In the present instance, I have pursued this understanding through a critique of the notion of preference, which, I think, has muddied the waters, drawing CA toward the probabilistic model of standard social science. 


\section{Appendix}

Rice division: Kammang transcription 25

1. dææng: pøø nøøy køø man: waa

2. dii: køø (.) uu bøøk h khing day [dii (lææw) løø=

3. dææng: [(thøøt)

4. dii: =khing bø fang: na khing (høøng) pattho (.) lon::: phæw baan

5. kææ baan khwææn [bn (=pun)

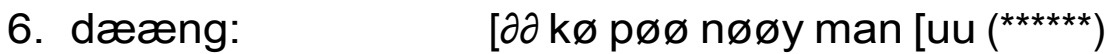

7. kææw:

[kø pøø nøøy waa huu

8. khaa luu (.) mææn køø (.8)

9. dii)-- ${ }^{\circ} \mathrm{mhm}^{\circ}$

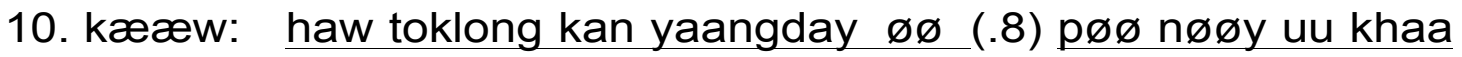

11. yaang day (.8) khaa kø thaam nøø (.) ca hut khaa nyia'

12. yaangyay (.8) huu-khing nyia' pay taløøt $\mathrm{t} \partial(.5)$ aw con khing

13. kaay (5)

14. dii: bøø [waa (.) annii bø day waa (.8) bø day waa

15. kææw: [mua khing ba kaay (1) mua khing ba kaay (.8) cawnaa

16. (ca) thøøt day yaang day (.) [bø waa $\left({ }^{*}\right)$ waa nay (suan han løø)

17. ?:

18. dii: uu $\left[\left(^{*}\right) 19\right.$.

$\left[\left(^{*}\right)\right.$

19. ?: uu $\left[\left(^{*}\right)\right.$

20. kææw: $\left(^{*}\right)$ waa han

21. dii: ca pay uu hææng aay huu pan

22. kææw: ooo (.5) mii yaang day khaa uu yaang an nan a

23. dææng: (kø khøy) uu [kan na

24. dii:

25. kham baan han nia

26. kææw: næænøøn (.5) pay thaam nyia naa (.) thaa pøø nøøy bø

27. huu nyia naa khaa pay nyia

28. (dææng): $\left({ }^{* * *}\right)$

29. kææw: $\partial \partial$ læ køø pøø nøøy waa yang thaam khaa tii an (.5)

30. høøng (.) pii can nyang naa (.5) (aw) lok khaaw day taday

31. (.8) day ta an khing ba pøø kin ia pøø nøøy waa ba waa (1.5)

32. [waa kø (.5) [kam bot nii waa kø (2)

33. (?):

34. (?):

$\left[\left(^{*}\right)\right.$

35. dii: waa $\left[\left(^{* * *}\right)\right.$

36. mu:n: [aw ii t $\partial$ (.) (uy) naa[n waa $\left(^{*}\right)$

37. kææw:

[bøø waa yaangday uu kan nay

\footnotetext{
$\overline{25}$ I have not included tone markers. Speakers of Kammang (Northern Thai) should be able to figure them out without undue trouble
} 
38. suan naa haan pøø nøøy (.) khaa ba luum naa

39. dii: iido[m (.) iidom pen khon cak cuung khing maa nyia' ni (1.5)

40. kææw: [khaa ba cay thaw naa

41. dææng: mææn iidom pen khon [cak (cuung)

42. kææw:

$[\partial \partial$ (.) [iidom maa cak cuung (.) [nø

43. ?:

$\left[\left({ }^{* *}\right)\right.$

44. dææng:

[la

45. man naaa man ba cay pen khøøng ii[dom a man khang pen= 46. dii:

[la bødiaw ni naa

47. dææng: =khøøng ii pøø [nøøy a iaa

48. dii:

[man-

49. dii: man pen pay [ii naa

50. dææng: [kø thaa waa ii[pøø nøøy ba huu nyia $k \varnothing=$

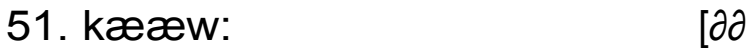

52. dææng: =haw kø tung nyia' ba day pøø nøøy [toklong huu haw=

53. ?:

[(ca waa pay kø

54. pen) $\left(^{*}\right)$ (iidom) $\left(^{*}\right)$

55. =nyia' lææw køø thaam kan la lø:

56. kææw: $\partial \partial$ taa phay ba (h)hu(h)a hehhaha bø waa hahaha

57 


\section{References}

Atkinson, Maxwell J., Drew, Paul, 1979. Order in Court: The Organization of Verbal Interaction in Judicial Settings. Humanities Press, Atlantic Highlands, NJ.

Bilmes, Jack, 1986. Discourse and Behavior. Plenum, New York.

Bilmes, Jack, 1988. The concept of preference in conversation analysis. Language in Society 17 (2), 161--181.

Bilmes, Jack, 1991. Toward a theory of argument in conversation: the preference for disagreement. In: van Eemeren, F.H., Grootendorst, R., Blair, J.A., Willard, C.A. (Eds.), Proceedings of the Second International Conference on Argumentation. SICSAT. International Centre for the Study of Argumentation, Amsterdam, pp. 462-469.

Bilmes, Jack, 1992. Dividing the rice: a microanalysis of the mediator's role in a Northern Thai negotiation. Language in Society 21 (4), 569-- 602.

Bilmes, Jack, 1993. Ethnomethodology, culture, and implicature: toward an empirical pragmatics. Pragmatics 3 (4), 387--409. Bilmes, Jack, 1994.

Constituting silence: life in the world of total meaning. Semiotica 98 (1/2), $73--87$.

Bilmes, Jack, 1995a. Negotiation and compromise: a microanalysis of a discussion in the Federal Trade Commission. In: Firth, A. (Ed.), The Discourse of Negotiation: Studies of Language in the Workplace. Pergamon Press, Oxford, pp. 61--81.

Bilmes, Jack, 1995b. Dividing the rice II: achieving agreement. In: Bilmes, L., Liang, A.C., Ostapirat, W. (Eds.), Special Session on Discourse in Southeast Asian Languages: Proceedings of the Twenty-First Annual Meeting of the Berkeley Linguistics Society. Braun-Brumfield. Ann Arbor, Michigan, pp. 16--32.

Bilmes, Jack, 1999. Questions, answers, and the organization of talk in the 1992 vice presidential debate: fundamental considerations. Research on Language and Social Interaction 32 (3), 213--242.

Bilmes, Jack, 2001. Tactics and styles in the 1992 vice-presidential debate: question placement. Research on Language and Social Interaction 34 (2), 151--181.

Bilmes, Jack, 2009. Kinship categories in a Northern Thai narrative. In: Nguyen, $H_{\text {., }}$ Kasper, G. (Eds.), Talk-in-Interaction: Multilingual Perspectives. University of Hawaii National Foreign Language Resource Center, Honolulu, HI, pp. 29--56.

Bilmes, Jack, 2012. Truth and proof in a lawyer's story. Journal of Pragmatics 44 (12), 1626--1638.

Button, Graham, Lee, J.R.E. (Eds.), 1987. Talk and Social Organization. Multilingual Matters, Clevedon.

Clayman, Steven E., Heritage, John, 2002. Questioning presidents: journalistic deference and adversarialness in the press conferences of U.S. presidents Eisenhower and Reagan. Journal of Communication 52 (4), 749--775. 
Davidson, Judy, 1984. Subsequent versions of invitations, offers, requests, and proposals dealing with potential or actual rejection. In: Atkinson, J. M., Heritage, J. (Eds.), Structures of Social Action: Studies in Conversation Analysis. Cambridge University Press, Cambridge, pp. 102--128.

Dersley, Ian, Wootton, Anthony, 2000. Complaint sequences within antagonistic argument. Research on Language and Social Interaction 33 (4),375--406.

Drew, Paul, 1985. Analyzing the use of language in courtroom interaction. In: van Dijk, T.A. (Ed.), Handbook of Discourse Analysis 3. Academic Press, London, pp. 133-147.

Drew, Paul, 1992. Contested evidence in courtroom cross-examination: the case of a trial for rape. In: Drew, P., Heritage, J. (Eds.), Talk at Work: Interaction in Institutional Settings. Cambridge University Press, Cambridge, pp. 470--520.

Enfield, N.J., Stivers, Tanya (Eds.), 2007. Person Reference in Interaction: Linguistic, Cultural, and Social Perspectives.. Cambridge University Press, Cambridge.

Garfinkel, Harold, 1967. Studies in Ethnomethodology. Prentice-Hall, Englewood Cliffs, New Jersey.

Goodwin, Marjorie Harness, 1983. Aggravated correction and disagreement in children's conversations. Journal of Pragmatics 7 (6), 657--677.

Gruber, Helmut, 1998. Disagreeing: sequential placement and internal structure of disagreements in conflict episodes. Text 18 (4), 467--503.

Gruber, Helmut, 2001. Questions and strategic orientation in verbal conflict sequences. Journal of Pragmatics 33 (12), 1815--1857.

Heritage, John, 1984. Garfinkel and Ethnomethodology. Polity, Cambridge.

Heritage, John, Watson, Rod D., 1979. Formulations as conversational objects. In: Psathas, G. (Ed.), Everday Language: Studies in Ethnomethodology. Irvington Publishers, New York, pp. 123--162.

Howard, Alan, 1982. Interactional psychology: some implications for psychological anthropology. American Anthropologist 84 (1), 37--57.

Kakava, Christina, 2002. Opposition in modern Greek discourse: cultural and contextual constraints. Journal of Pragmatics 34 (10--11), 1537-- 1568.

Kotthoff, Helga, 1993. Disagreement and concession in disputes: on the context sensitivity of preference structures. Language in Society 22 (2), 193--216.

Langendoen, Terrence D., 1971. Presupposition and assertion in the semantic analysis of nouns and verbs in English. In: Steinberg, D., Jakobovits, L. (Eds.), Semantics: An Interdisciplinary Reader in Philosophy, Linguistics and Psychology. Cambridge University Press, Cambridge, pp. 341--344.

Lazaraton, Anne, 1991. A Conversation Analysis of Structure and Interaction in the Language Interview. (Ph.D. dissertation) Department of TESL and Applied Linguistics, University of California, Los Angeles.

Lazaraton, Anne, 1997. Preference organization in oral proficiency interviews: the case of language ability assessments. Research on Language and Social Interaction 30 (1), 53--72.

Leech, Geoffrey N., 1983. Principles of Pragmatics. Longman, London.

Lerner, Gene H., 1996. Finding 'face' in the preference structures of talk-ininteraction. Social Psychological Quarterly 59, 303--321. Levenson, Stephen C., 1983. Pragmatics. Cambridge University Press, Cambridge. 
the request to participate in a telephone survey interview.

Sociological Methods and Research 26 (1), 34--79.

Meyer, Christian, 2010. Self, Sequence and the Senses: Universal and Culture-Specific Aspects of Conversational Organization in a Wolof Social Space. (Habilitationschrift) Eingereicht an der Fakultat fur Soziologie der Universitat Bielefeld, Bielefeld.

Mushin, Ilana, Gardner, Rod, 2009. Silence is talk: conversational silence in Australian aboriginal talk-in-interaction. Journal of Pragmatics 41 (10), 2033--2052.

Philips, Susan Urmston, 1976. Some sources of cultural variability in the regulation of talk. Language in Society 5 (1), 81--95.

Pomerantz, Anita, 1975. Second Assessments: A Study of Some Features of Agreements/Disagreements. (Ph.D. dissertation) University of California, Irvine.

Pomerantz, Anita, 1978. Compliment responses: notes on the co-operation of multiple constraints. In: Schenkein, J. (Ed.), Studies in the Organization of Conversational Interaction. Academic Press, New York, pp. 79--112.

Pomerantz, Anita, 1984. Agreeing and disagreeing with assessments: some features of preferred/dispreferred turn shapes. In: Atkinson, J.M., Heritage, J. (Eds.), Structures of Social Action: Studies in Conversation Analysis. Cambridge University Press, Cambridge, pp. 57--101.

Pomerantz, Anita, Heritage, John, 2012. Preference. In: Sidnell, J., Stivers, T. (Eds.), The Handbook of Conversation Analysis. Wiley-Blackwell, Chichester, West Sussex, pp. 210--228.

Popper, Karl R., 1959. The Logic of Scientific Discovery. Hutchinson, London (First published in German in 1935.).

Robinson, Jeffrey D., 2007. The role of numbers and statistics within conversation analysis. Communication Methods and Measures 1 (1), 65--75.

Sacks, Harvey, 1987 [1973]. On the preferences for agreement and contiguity in sequences in conversation. In: Button, G., Lee, J.R.E. (Eds.), Talk and Social Organization. Multilingual Matters, Clevedon, pp. 54--69.

Sacks, Harvey, 1992. In: Jefferson, G. (Ed.), Lectures on Conversation, vol. 1. Blackwell, Oxford.

Sacks, Harvey, Schegloff, Emanuel A., 1979. Two preferences in the organization of reference to persons in conversation and their interaction. In: Psathas, G. (Ed.), Everday Language: Studies in Ethnomethodology. Irvington Publishers, New York, pp. 15--21.

Sacks, Harvey, Schegloff, Emanuel A., Jefferson, Gail, 1974. A simplest systematics for the organization of turn-taking for conversation. Language 50 (4), 696--735.

Schegloff, Emanuel A., 1968. Sequencing in conversational openings. American Anthropologist 70 (6), 1075--1095.

Schegloff, Emanuel A., 1993. Reflections on quantification in the study of conversation. Research on Language and Social Interaction 26 (1), 99-- 128.

Schegloff, Emanuel A., 2007. Sequence Organization in Interaction: A Primer in Conversation Analysis, vol. 1. Cambridge University Press, Cambridge.

Schegloff, Emanuel A., Jefferson, Gail, Sacks, Harvey, 1977. The preference for selfcorrection in the organization of repair in conversation.

Language 53 (2), 361--382.

Scollon, Ronald, Wong-Scollon, Suzanne, 1990. Athabaskan-English interethnic communication. In: Carbaugh, D. (Ed.), Cultural Communication and Intercultural Contact. Lawrence Erlbaum, Hillsdale, NJ, pp. 259--286.

Sidnell, Jack, 2010. Conversation Analysis: An Introduction. Wiley-Blackwell, Chichester, West Sussex. 
Sidnell, Jack, Stivers, Tanya (Eds.), 2012. The Handbook of Conversation Analysis. Wiley-Blackwell, Chichester, West Sussex. Stivers, Tanya, Robinson, Jeffrey D., 2006. A preference for progressivity in interaction. Language in Society 36 (3), 367--392.

Tannen, Deborah, 1984. Conversational Style: Analyzing Talk among Friends. Ablex Publishing, Norwood, NJ.

Tannen, Deborah, 2012. Turn-taking and intercultural discourse and communication. In: Paulston, C.B., Kiesling, S.F., Rangel, E.S. (Eds.), The Handbook of Intercultural Discourse and Communication. Blackwell, Oxford.

Zimmerman, Don H., 1993. Acknowledgment tokens and speakership incipiency. Research on Language and Social Interaction 26 (2), 179-194. 